\title{
ANÁLISE PRELIMINAR DA (IM)PERMEABILIZAÇÃO DO SOLO NA SUB-BACIA BARREIRINHA, PORÇÃO NORTE DA BACIA DO RIO BELÉM (CURITIBA- PR)
}

\author{
Geisa Silveira da Rocha ${ }^{(a)}$, Otacílio Lopes de Souza da Paz ${ }^{(b)}$ \\ ${ }^{(a)}$ Doutoranda do Curso de Pós Graduação em Geografia da Universidade Federal do Paraná, geisa_sr@hotmail.com

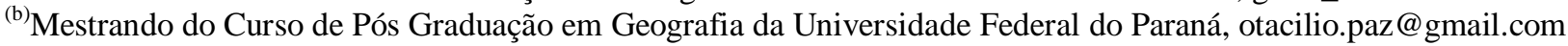

\section{EIXO: BACIAS HIDROGRÁFICAS E RECURSOS HÍDRICOS: ANÁLISE, PLANEJAMENTO E GESTÃO}

\begin{abstract}
Resumo
A bacia do rio Belém está localizada no município de Curitiba (Paraná) e é historicamente explorada para diversos usos, a porção norte é onde se encontram as nascentes do rio Belém. A presente pesquisa constitui-sede um trabalho realizado na disciplina "Ecologia e planejamento da paisagem", ministrada pelo professor Dr. João Carlos Nucci, oferecida pelo Programa de Pós Graduação em Geografia da Universidade Federal do Paraná, no primeiro semestre de 2017. O objetivo do trabalho foi de inferir a impermeabilização da superfície com base no mapeamento da cobertura da terra. $\mathrm{O}$ mapeamento da impermeabilização mostrou que mais da metade da área de estudo está coberta por material impermeável, sendo $29 \%$ totalmente impermeável e $45 \%$ parcialmente impermeável. Aproximadamente $26 \%$ da área é considerada como de superfície permeável, o que acaba diminuindo a qualidade ambiental da bacia do rio Belém e potencializando os riscos de inundação e assoreamento.
\end{abstract}

Palavras chave: Geotecnologias; Planejamento; Rio Belém; Impermeabilização; Cobertura da terra.

\section{Introdução}

Este trabalho é resultado de uma pesquisa realizada durante a disciplina de "Ecologia e planejamento da paisagem" ministrada pelo professor Dr. João Carlos Nucci, durante o primeiro semestre de 2017, ofertada pelo programa de pós graduação em Geografia da Universidade Federal do Paraná (UFPR). A disciplina trouxe a reflexão da paisagem como objeto de investigação para a Geografia, mostrando que o planejamento da paisagem pode ser um instrumento de importância significativa para a proteção e gestão da natureza.

A bacia hidrográfica do rio Belém está situada no município de Curitiba (Paraná), seu talvegue principal atravessa a cidade no sentido norte-sul, passando por pontos variados na cidade, desde parques até áreas densamente urbanizadas, ocupando $84 \mathrm{~km}^{2}$ com sua área de drenagem correspondendo a aproximadamente 20\% do território de Curitiba (BOLLMANN; EDWIGES, 2008). A área de estudo compreende a porção norte da bacia, à montante do parque São Lourenço (Figura 1), inserida parcialmente entre os bairros Barreirinha, Abranches, Cachoeira e São Lourenço. 

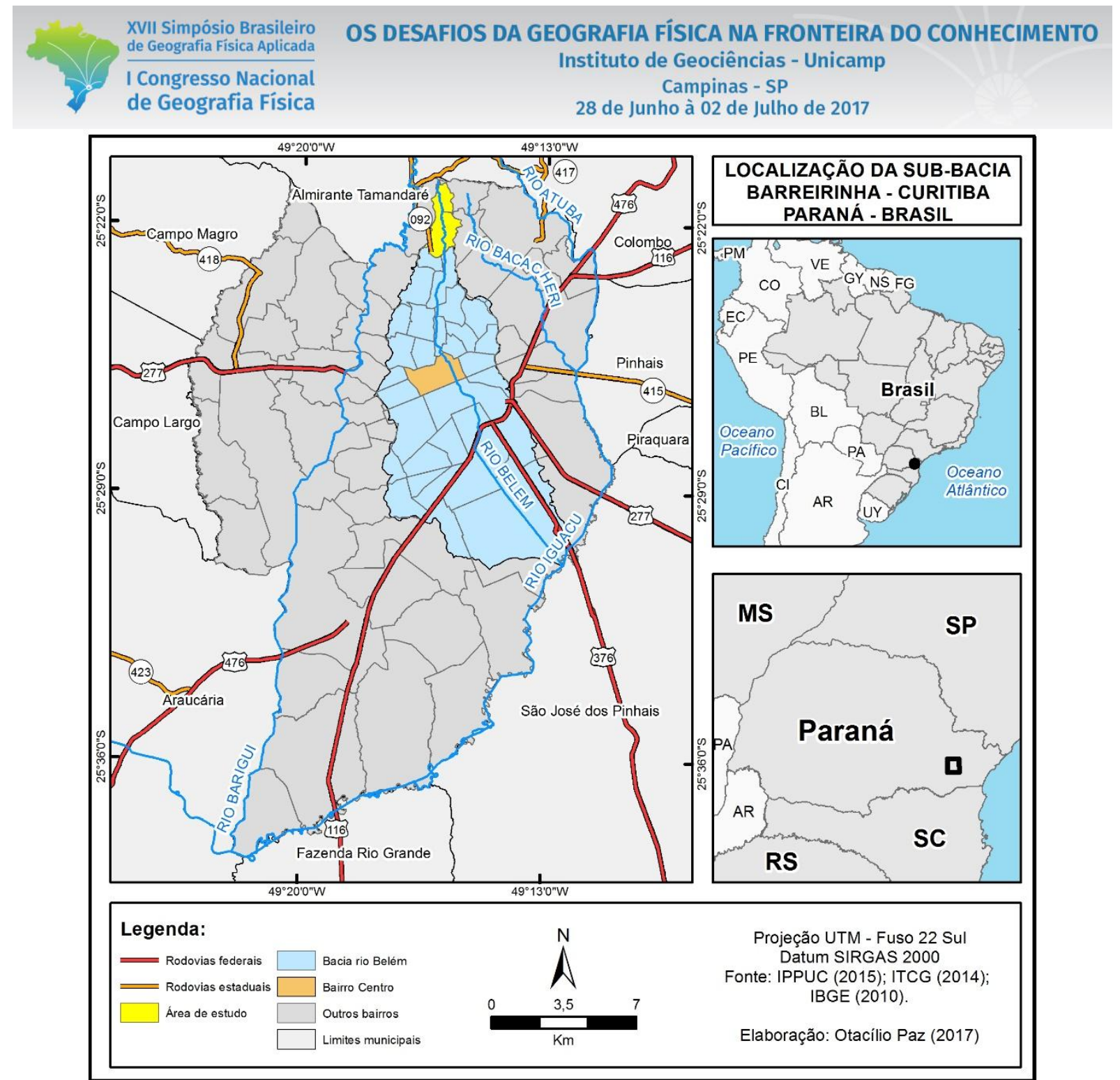

Figura 1 - Localização da área de estudo. Fonte: Os autores (2017).

Apesar de toda sua importância socioeconômica, as águas da bacia do rio Belém se encontram em sua maior parte poluídas e contaminadas. Um estudo realizado por Bollmann e Edwiges (2008) mostrou que a qualidade da água diminui progressivamente da nascente até sua foz, com o trecho da região central da bacia (Rios Ivo, Juvevê e Água Verde) apresentando os piores resultados.

Além da poluição das águas, é possível identificar problemas relacionados à diminuição da infiltração da água no solo, o que pode causar inundações e também assoreamento do rio(BOLLMANN; EDWIGES, 2008). Desta maneira, o presente trabalho busca inferir a impermeabilização da superfície do solo, entendido como a cobertura permanente de uma dada superfície com materiais artificiais impermeáveis. Para Nucci (2008, p.13), o aumento da impermeabilização do solo nas áreas urbanas faz com que "os corpos d'água e os espaços livres vegetados não encontram lugar na luta pelo espaço. A verticalização faz com que a superfície de concreto, com alta capacidade térmica, aumente". 


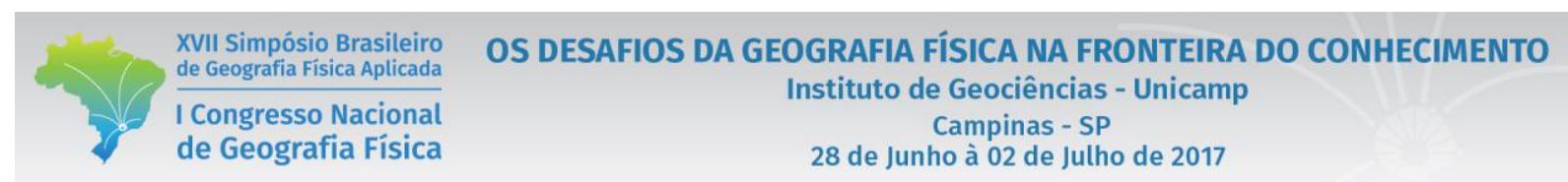

\section{Metodologia}

A sub-bacia Barreirinha situa-se na porção norte da bacia do rio Belém, onde se localizam as nascentes do rio Belém (figura 2). A bacia possui aproximadamente $3,5 \mathrm{~km}^{2}$, limitada a oeste pela bacia do rio Barigui e a leste pela bacia do rio Bacacheri. Entre os pontos de interesse na sub-bacia, cabe destacar um cemitério ao norte do Parque das Nascentes do Rio Belém e a Vila Diana na porção central da área de estudo.

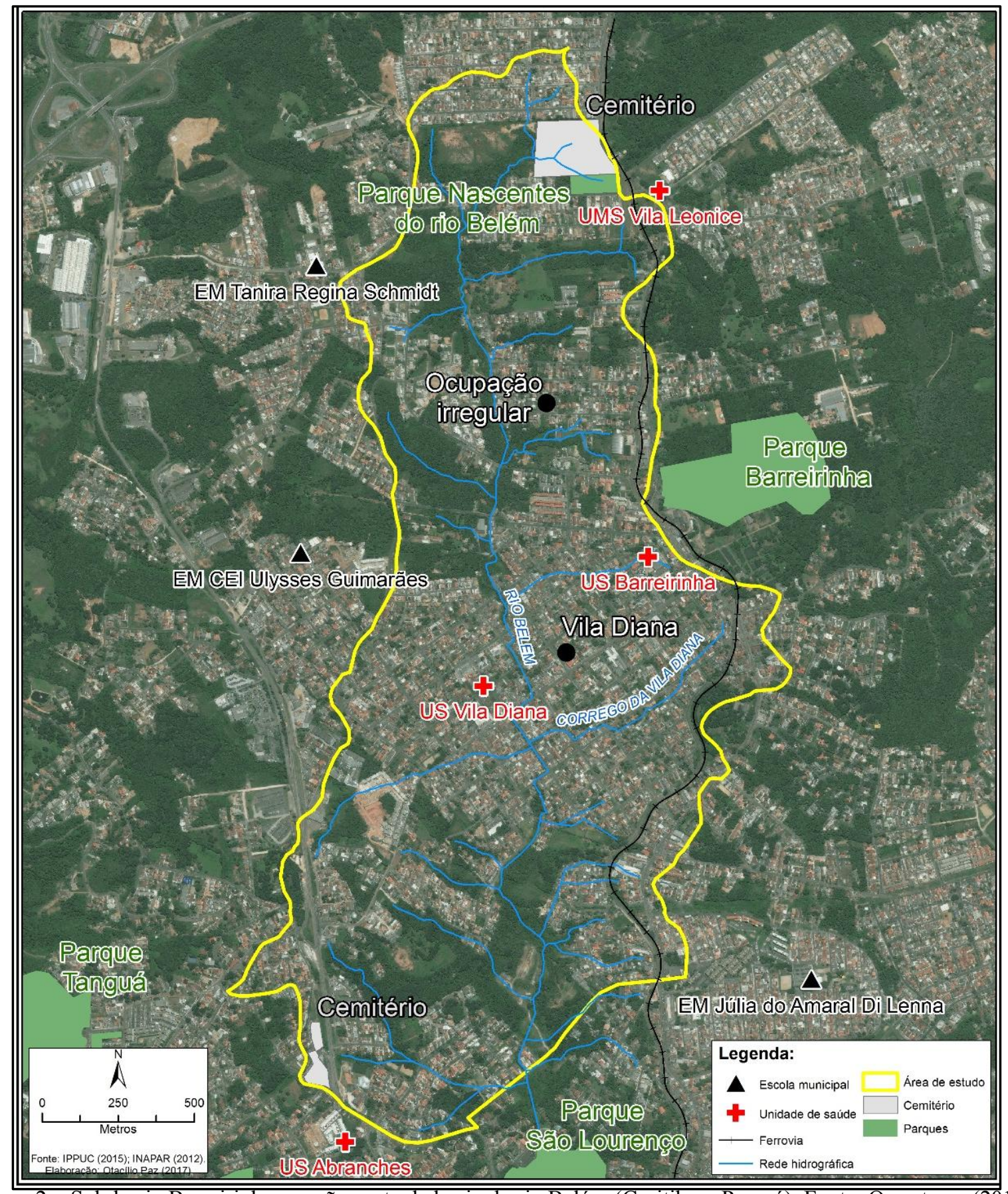

Figura 2 - Sub-bacia Barreirinha, porção norte da bacia do rio Belém (Curitiba - Paraná). Fonte: Os autores (2017). 


\section{OS DESAFIOS DA GEOGRAFIA FÍSICA NA FRONTEIRA DO CONHECIMENTO \\ Instituto de Geociências - Unicamp \\ Campinas - SP \\ 28 de Junho à 02 de Julho de 2017}

Para identificação da impermeabilização do solo e o mapeamento dessas áreas, a metodologia adotada foi realizar inicialmente o mapeamento da cobertura da terra. A partir de imagens de satélite do acervoGoogle Earth (2016) na escala aproximada 1:5.000 e trabalho de campo, foi feito primeiramente um trabalho manual como base visual de interpretação da paisagem, utilizando para isso o papel do tipo vegetal. Sob o papel vegetal foi traçado as quadras para posterior classificação, seguindo a proposta de legenda realizada por Nucci et al. (2014) e adotada por Ferreira (2015) no trabalho de dissertação em que elaborou uma carta da qualidade ambiental de Curitiba com base no mapeamento da cobertura da terra.

A segunda etapa do trabalho foi transpor as informações do mapa realizado manualmente para um Sistema de Informação Geográfica (SIG). O software utilizado foi o ArcGIS versão 10.1. A figura 3 mostra a legenda adotada no mapeamento da cobertura da terra na sub-bacia Barreirinha.

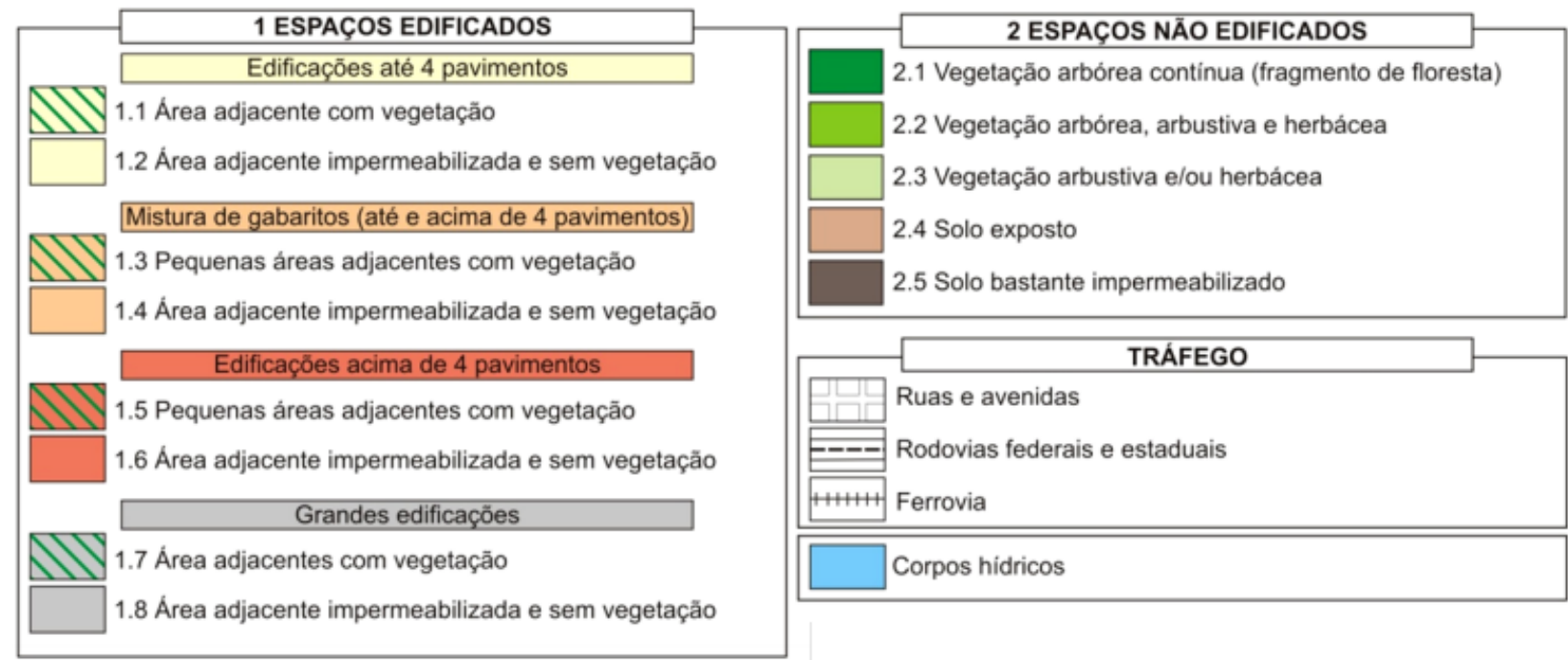

Figura 3 - Legenda de cobertura da terra proposta por Nucci et al. (2014). Fonte: Nucci et al. (2014)

A terceira etapa constituiu a elaboração da carta de impermeabilização do solo, realizada a partir das classes de legenda da carta de cobertura da terra (FERREIRA, 2015), na qual foram definidas três classes de permeabilidade: melhor, médio e pior. As classes de permeabilidade foram definidas pelo agrupamento de classes da cobertura da terra e arruamento, divididos em espaços edificados e espaços não-edificados. Seguido dos números 1 (pior permeabilidade), 2 (média permeabilidade), 3 (melhor permeabilidade), conforme indica o quadro I e figura 4.

Quadro I - Classes de cobertura identificadas na área de esudo da terra e permeabilidade

\begin{tabular}{|l|c|}
\hline Cobertura da Terra & Classe \\
\hline 1.1 até 4 pavimentos e áreas adjacentes com vegetação & 2 \\
\hline 1.2 até 4 pavimentos, com área adjacente impermeabilizada e sem vegetação & 1 \\
\hline
\end{tabular}


XVII Simpósio Brasileiro de Geografia Física Aplicada

I Congresso Nacional de Geografia Fisica
OS DESAFIOS DA GEOGRAFIA FÍSICA NA FRONTEIRA DO CONHECIMENTO

Instituto de Geociências - Unicamp

Campinas - SP

28 de Junho à 02 de Julho de 2017

\begin{tabular}{|l|c|}
\hline 1.7 grandes edificações com vegetação nas áreas adjacentes & 2 \\
\hline $\mathbf{1 . 8}$ grandes edificações, com área adjacente impermeabilizada e sem vegetação & 1 \\
\hline $\mathbf{2 . 1}$ vegetação arbórea contínua & 3 \\
\hline $\mathbf{2 . 2}$ vegetação arbórea, arbustiva e herbácea & 3 \\
\hline $\mathbf{2 . 3}$ vegetação arbustiva e/ou herbácea & 3 \\
\hline $\mathbf{2 . 4}$ solo exposto & 3 \\
\hline $\mathbf{2 . 5}$ solo bastante impermeabilizado & 1 \\
\hline Arruamento & 3 \\
\hline
\end{tabular}

Fonte: adaptado de Nucci et al. (2014) e Ferreira (2015)

\begin{tabular}{ccc}
\hline Permeabilidade & Cores Atribuidas & Valores \\
\hline Piora & & 1 \\
Atençăo & 2 \\
Melhora & 3 \\
\hline
\end{tabular}

Figura 4 - Classes de permeabilidade do solo. Fonte: Ferreira (2015)

Após a confecção da carta de permeabilidade do solo, foi elaborado um perfil topográfico em papel milimetrado com auxílio da base planialtimétrica disponibilizado pelo Instituto das Águas do Paraná, na escala 1:10.000, sendo posteriormente convertido em formato digital por meio do software ArcGIS 10.1. Neste perfil foram incluídas no eixo vertical as classes de permeabilidade, a fim de se ter uma visão geral do escoamento na área de estudo e indenficar áreas suscetíveis à inundações.

\section{Resultados e discussão}

O mapeamento da cobertura da terra se mostrou um instrumento adequado para inferir sobre a impermeabilização do solo, sendo comumente utilizada para delimitar unidades de paisagem (NUCCI, 2008).

A carta de cobertura da terra é apresentada na figura 5. Predominamas áreas edificadas de até quatro pavimentos com vegetação nas áreas adjacentes, ocupando aproximadamente $45 \%$ da área de estudo 


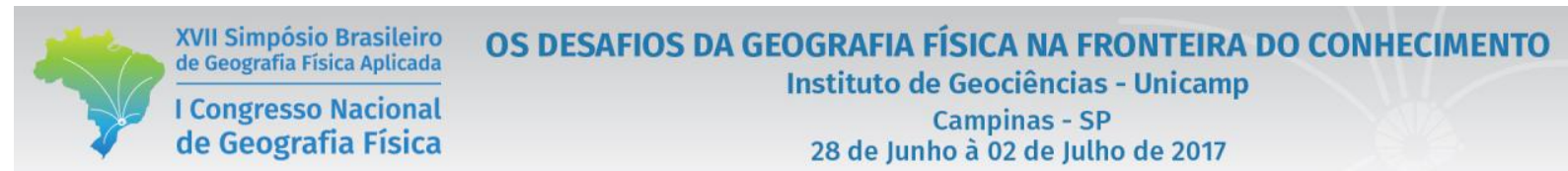

(quadro II). As áreas de vegetação arbórea com características de fragmentos florestais foram encontradas na porção norte.

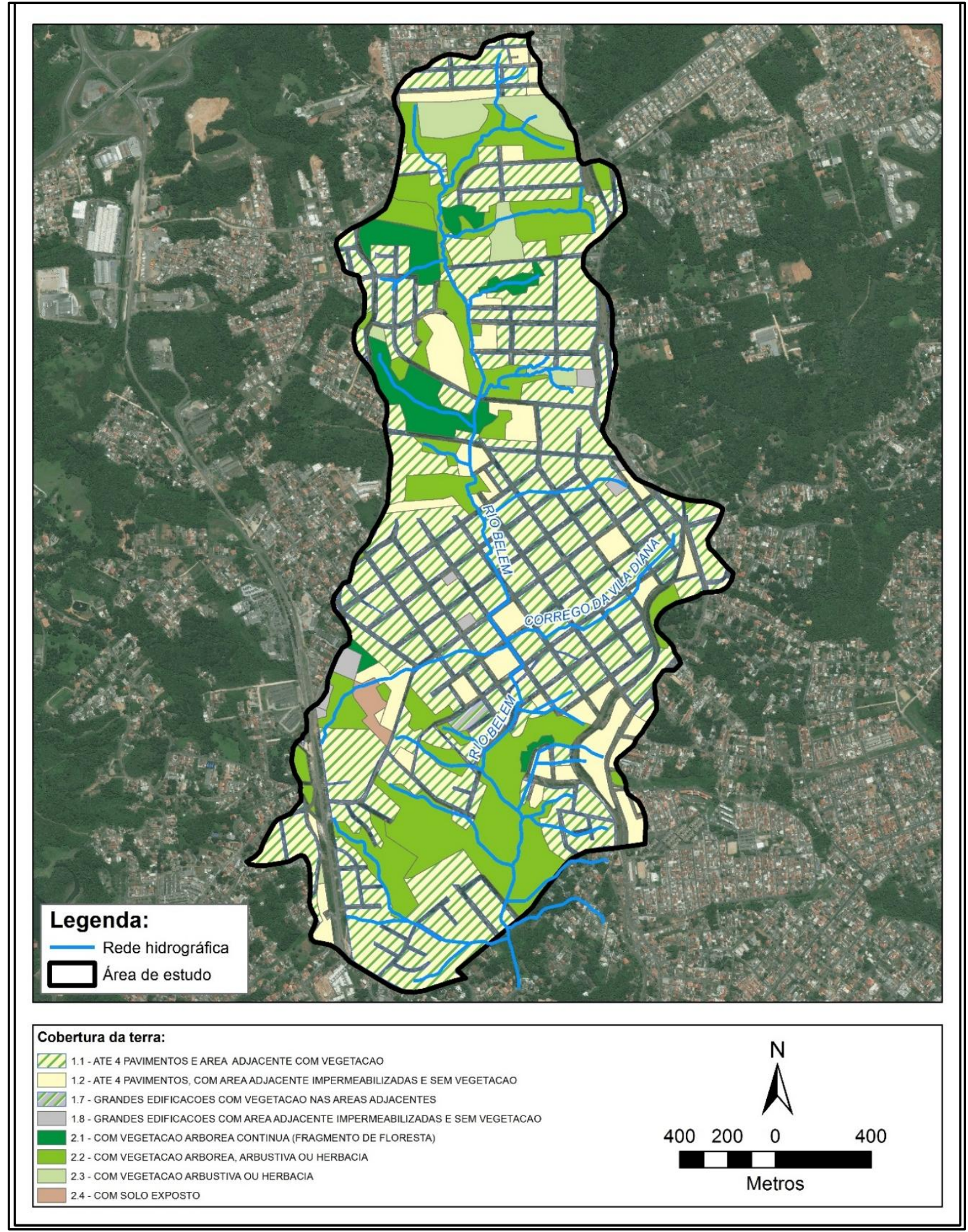

Figura 5 - Carta de cobertura da terra da sub-bacia Barreirinha (Curitiba - Paraná). Fonte: Os autores (2017).

Quadro II - Valores das classes de cobertura da terra. 
XVII Simpósio Brasileiro de Geografia Fisica Aplicada

I Congresso Nacional de Geografia Física
OS DESAFIOS DA GEOGRAFIA FÍSICA NA FRONTEIRA DO CONHECIMENTO

Instituto de Geociências - Unicamp

Campinas - SP

28 de Junho à 02 de Julho de 2017

\begin{tabular}{|c|c|c|c|c|}
\hline \multicolumn{3}{|c|}{ Classes de Cobertura da terra da sub-bacia Barreirinha } & Área & $\%$ \\
\hline \multirow{4}{*}{$\begin{array}{l}\text { EspaçosEdificados } \\
(53,93 \%)\end{array}$} & \multirow{2}{*}{ Grandesedificações } & $\begin{array}{l}\text { 1.1 Classes de Cobertura da terra do bairro } \\
\text { São Lourenço }\end{array}$ & 157,00 & $44,9 \%$ \\
\hline & & $\begin{array}{l}1.2 \text { área adjacente impermeabilizada e sem } \\
\text { vegetação }\end{array}$ & 28,00 & $8,00 \%$ \\
\hline & \multirow[b]{2}{*}{ Grandesedificações } & 1.7 áreaadjacente com vegetação & 0,8 & $0,25 \%$ \\
\hline & & $\begin{array}{l}1.8 \text { área adjacente impermeabilizada e sem } \\
\text { vegetação }\end{array}$ & 0,8 & $0,25 \%$ \\
\hline \multirow{6}{*}{$\begin{array}{l}\text { EspaçosNãoedificados } \\
\qquad(46,95 \%\end{array}$} & \multicolumn{2}{|c|}{ 2.1 Vegetação arbórea - Fragmento de Floresta } & 14,30 & $4,00 \%$ \\
\hline & \multicolumn{2}{|c|}{ 2.2 Vegetação arbórea, arbustiva e herbácea } & 64,50 & $18,5 \%$ \\
\hline & \multicolumn{2}{|c|}{ 2.3 Vegetação arbustiva e/ou herbácea } & 9,40 & $2,70 \%$ \\
\hline & \multicolumn{2}{|c|}{ 2.4 Solo exposto } & 1,80 & $0,50 \%$ \\
\hline & \multicolumn{2}{|c|}{ Espaços de integração viária (ruas, avenidas, estradas e ferrovias } & 71,00 & $20,20 \%$ \\
\hline & \multicolumn{2}{|l|}{ Corposhídricos } & 0,50 & $0,15 \%$ \\
\hline \multicolumn{3}{|c|}{ Total } & 350,00 & $100 \%$ \\
\hline
\end{tabular}

Com base na carta de cobertura da terra, foi inferida a permeabilidade do solo da área de estudo (figura 6). A carta de permeabilidade da terra é apresentada na figura 7. Predominam as áreas classificadas como"atenção", ocupando aproximadamente $45 \%$ da área de estudo (quadro III).

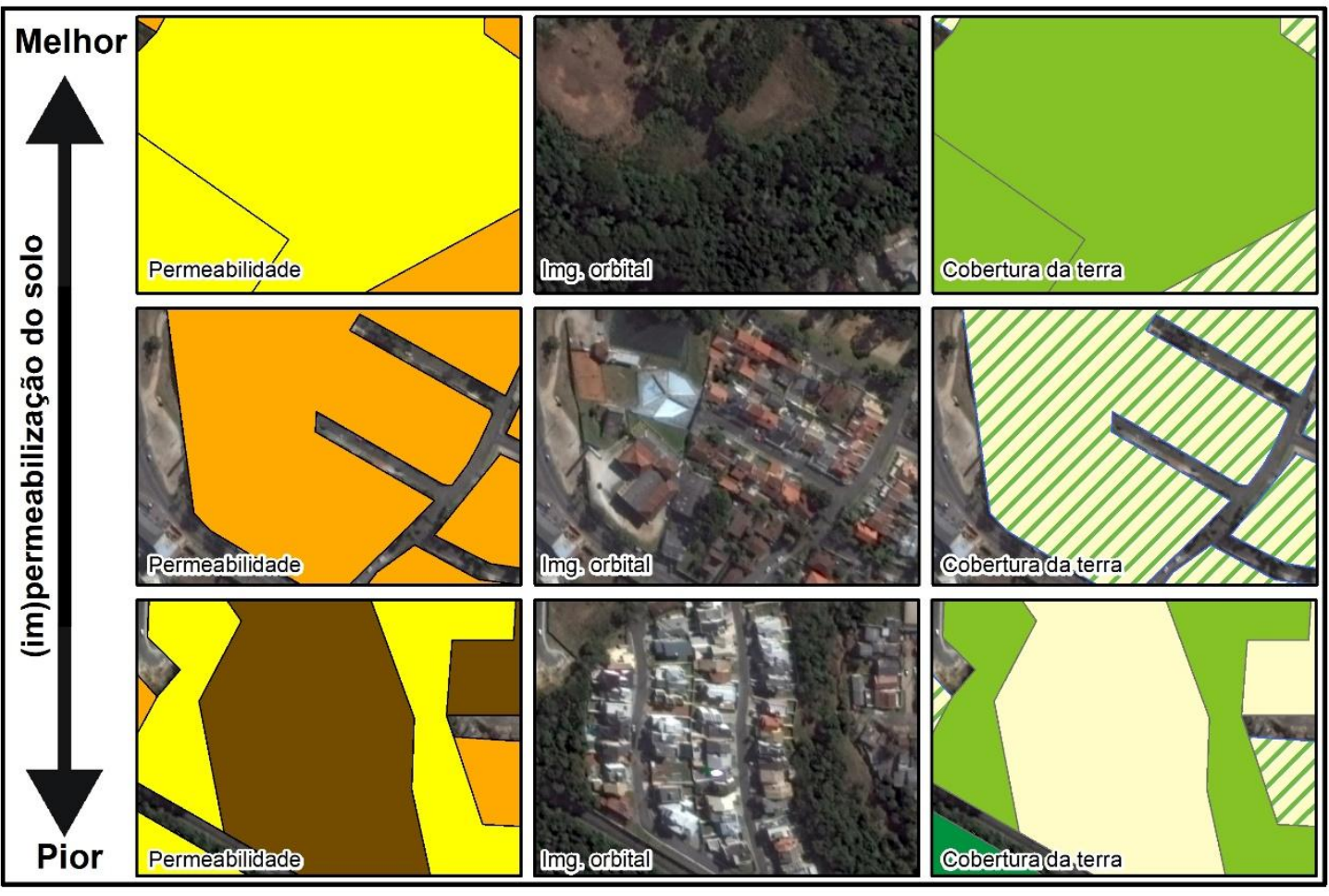

Classes de permeabilidade da sub-bacia Barreirinha. Escala aprox. 1:6.000. Fonte: Os autores (2017). 

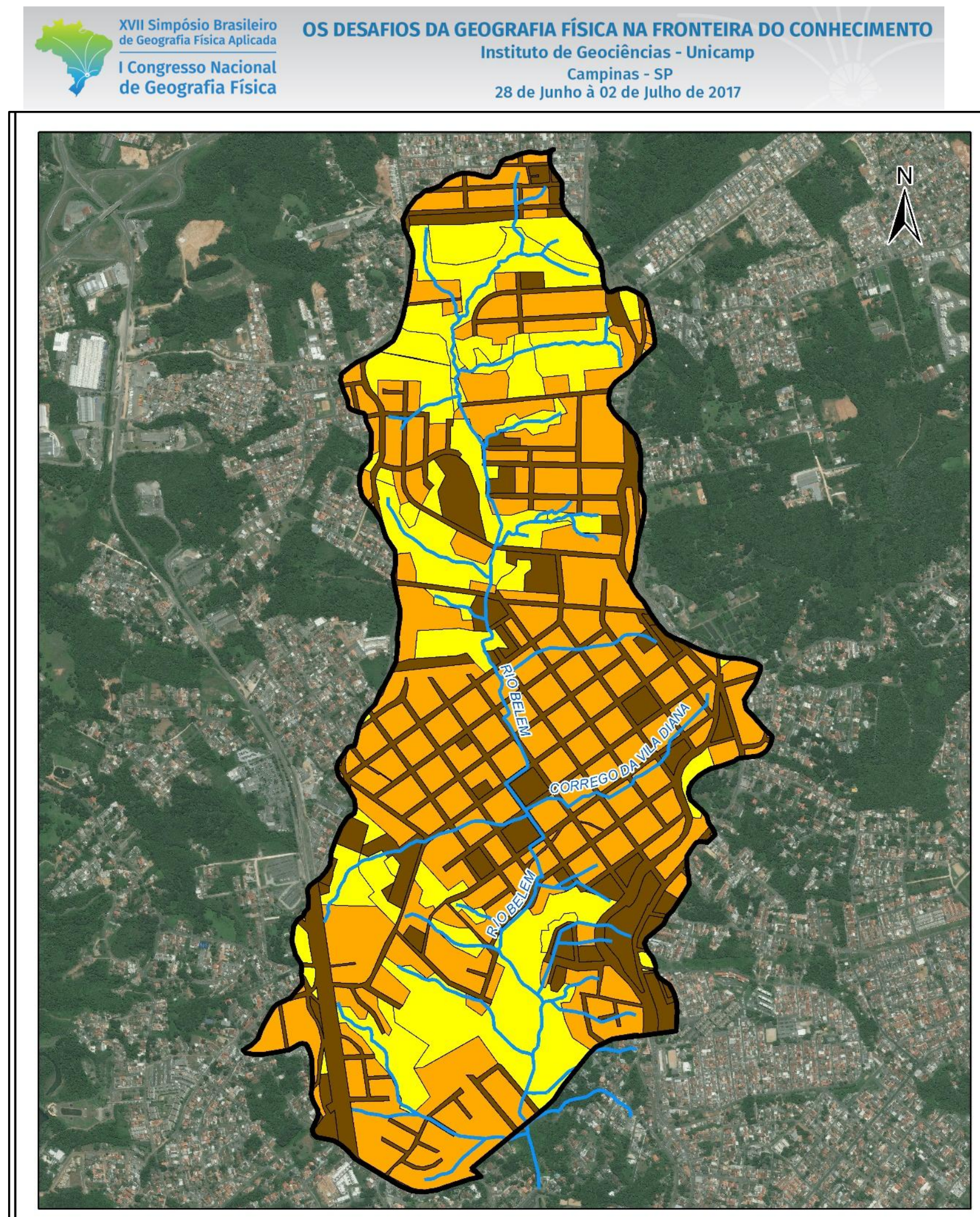

\section{Legenda: Permeabilidade:}

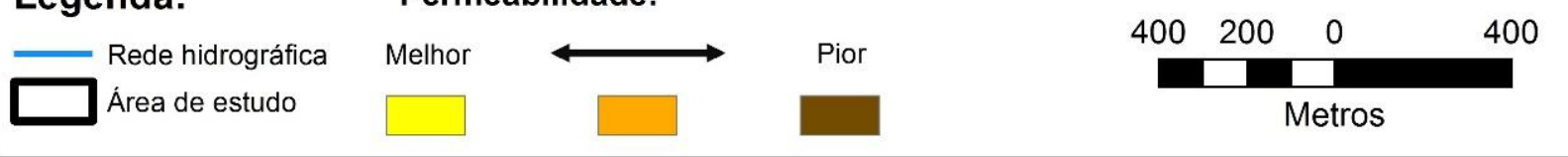

Figura 7 - Carta de permeabilidade do solo da sub-bacia Barreirinha (Curitiba - Paraná). Fonte: Os autores (2017). 


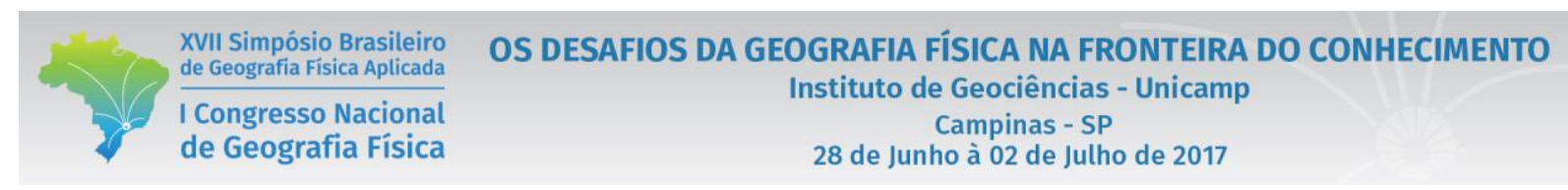

QuadroIII - Valores das classes de permeabilidade do solo

\begin{tabular}{|c|c|c|}
\hline Classe & Área $\mathbf{( k m}^{\mathbf{2}}$ ) & Porcentagem (\%) \\
\hline Pior & 1,00 & $29 \%$ \\
\hline Atenção & 1,58 & $45 \%$ \\
\hline Melhor & 0,92 & $26 \%$ \\
\hline Total & $\mathbf{3 , 5}$ & $\mathbf{1 0 0 \%}$ \\
\hline
\end{tabular}

A figura 8 apresenta o local da nascente do rio Belém e rio Belém a jusante da Vila Diana. Ás áreas com permeabilidade média, indicando atenção, representam aproximadamente $45 \%$ da área de estudo, sendo encontradas em toda esta área. As áreas com pior permeabilidade são encontradas de forma distribuídapela área de estudo, apresentando vários pontos na porção central, onde se localiza a Vila Diana (figura 9). Já as áreas com melhor permeabilidade do solo (figura 9), que representam aproximadamente $26 \%$ da área de estudo, localizando-se nas porções norte e sul, não sendo encontradas na porção central.
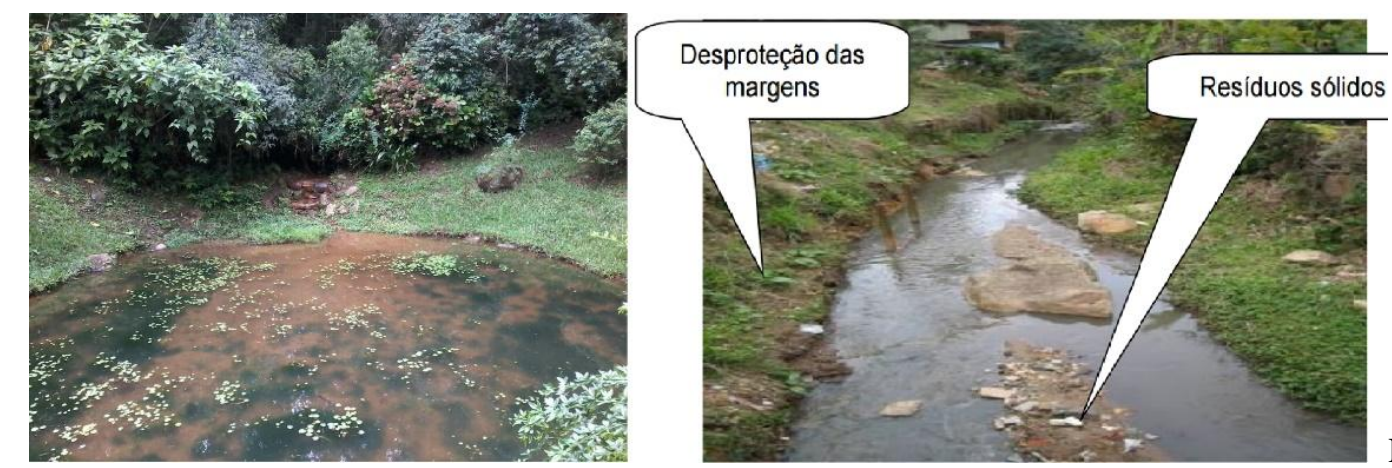

Figura 8 -

Esquerda: Parque Nascentes do rio Belém. Direita: rio Belém a jusante da Vila Diana. Fonte: Os autores (2017) e Edwiges (2006).
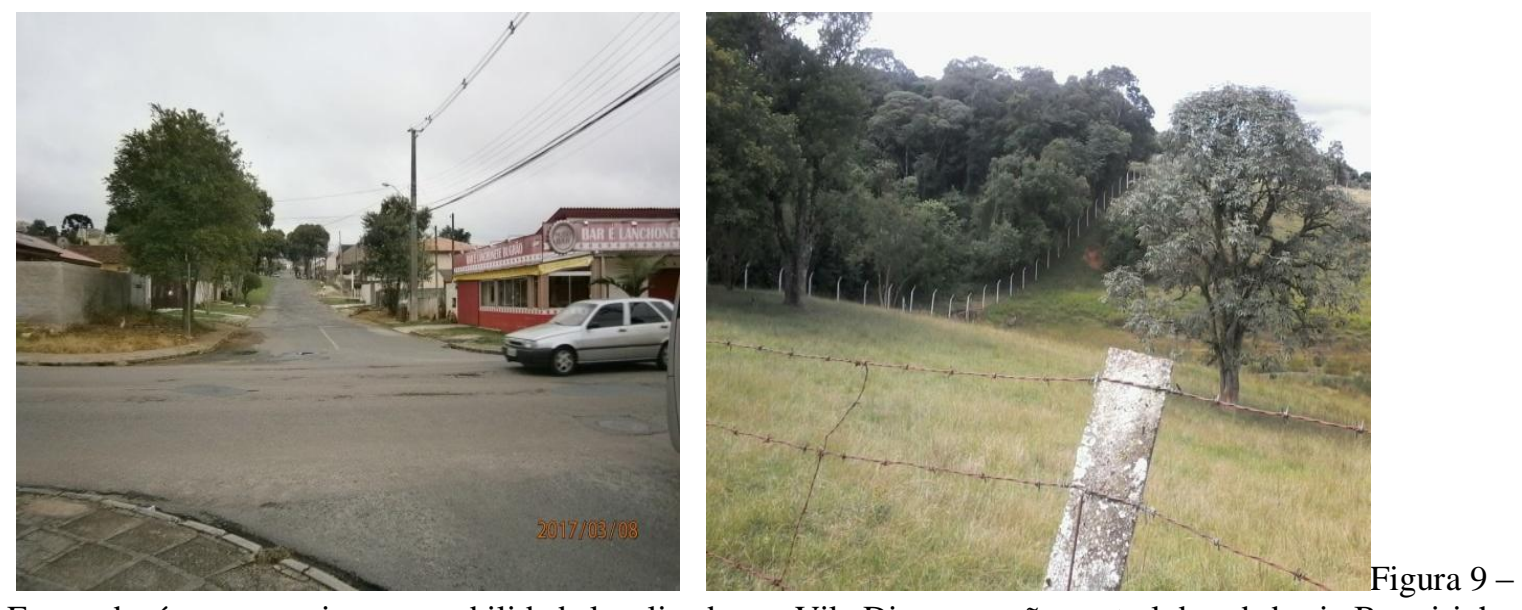

Esquerda: áreas com pior permeabilidade localizadas na Vila Diana, porção central da sub-bacia Barreirinha. Direita:Áreas com melhor permeabilidade localizadas na porção noroeste da sub-bacia Barreirinha, ao lado da ocupação irregular. Fonte: Os autores (2017).

A figura 10 representa o bloco diagrama da área de estudo, evidenciando a situação topográfica quanto a permeabilidade do solo. Nota-se que a Vila Diana se encontra inserida no fundo do vale do rio Belém. De acordo com a Defesa Civil, as áreas com círculos azuis já registraram casos de inundação. 

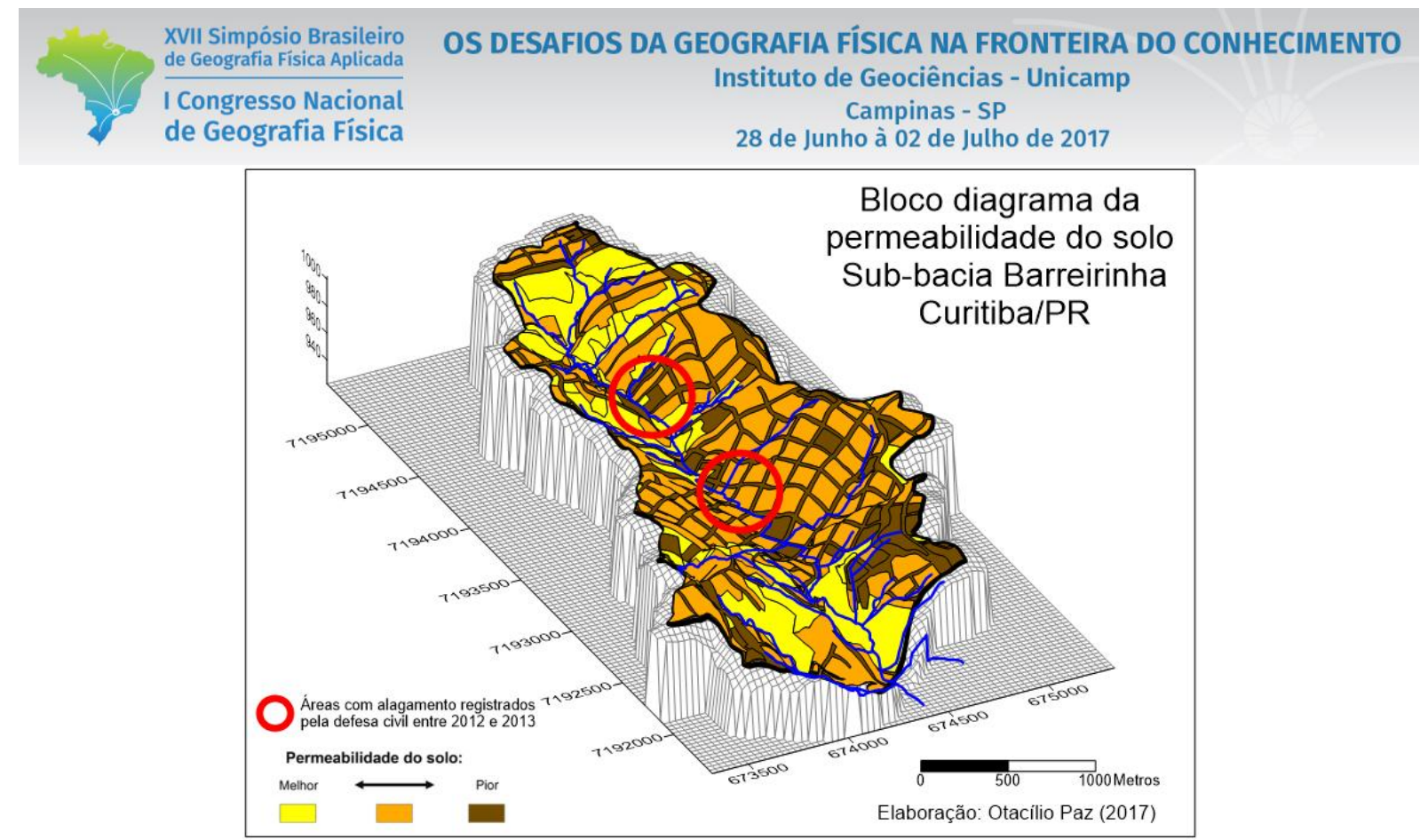

Figura 10 - Situação topográfica da área de estudo e casos de inundação registrados pela defesa cívil. Fonte: Os autores (2017).

Quanto ao rio Belém, com base na análise do perfil topográfico (figura 11), constata-se que este possui $59 \%$ de sua extensão (dentro da área de estudo) ocupado por áreas permeáveis (quadro IV). Cerca de 41\% estão ocupados por áreas impermeáveis, concentrando-se principalmente na Vila Diana (porção central).

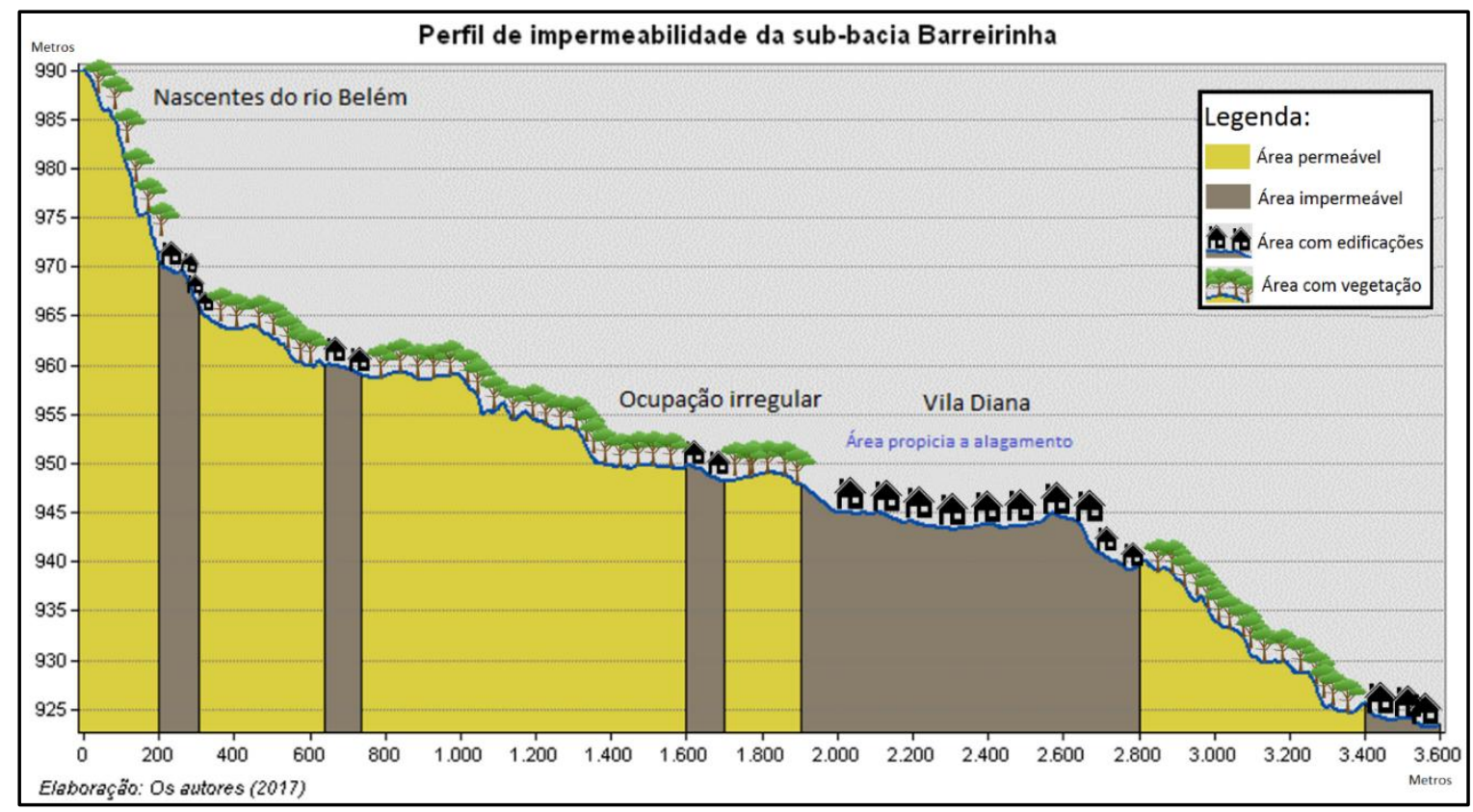

Figura 11 - Perfil de impermeabilidade da sub-bacia Barreirinha. Fonte: Os autores (2017).

QuadroIV - Permeabilidade do solo ao longo do rio Belém na sub-bacia Barreirinha.

\begin{tabular}{|c|c|c|}
\hline & Comprimento (km) & Porcentagem (\%) \\
\hline Permeável & 2,23 & $59 \%$ \\
\hline Impermeável & 1,57 & $41 \%$ \\
\hline
\end{tabular}


XVII Simpósio Brasileiro de Geografia Fisica Aplicada

I Congresso Nacional

de Geografia Física
OS DESAFIOS DA GEOGRAFIA FÍSICA NA FRONTEIRA DO CONHECIMENTO

Instituto de Geociências - Unicamp

Campinas - SP

28 de Junho à 02 de Julho de 2017

\begin{tabular}{l|r|r} 
Total & 3,8 & $100 \%$
\end{tabular}

Cabe ressaltar que a impermeabilização do solo como estratégia de higienização e saneamento urbano (na maioria das vezes decorrente do mau cheiro das águas dos rios e do impacto estético negativo da poluição na paisagem) é uma das principais causas de inundações e alagamentos em áreas urbanas, como verificado na figura 9 e 10; a área de estudo possui pontos de alagamento registrados pela Defesa Civil, este fato foi ratificado por uma moradora local da Vila Diana em que, durante o trabalho de campo, relatou inundações no bairro mesmo com obras de intervenção (figura 12). A figura 13 mostra parte do rio Belém sem alteração.
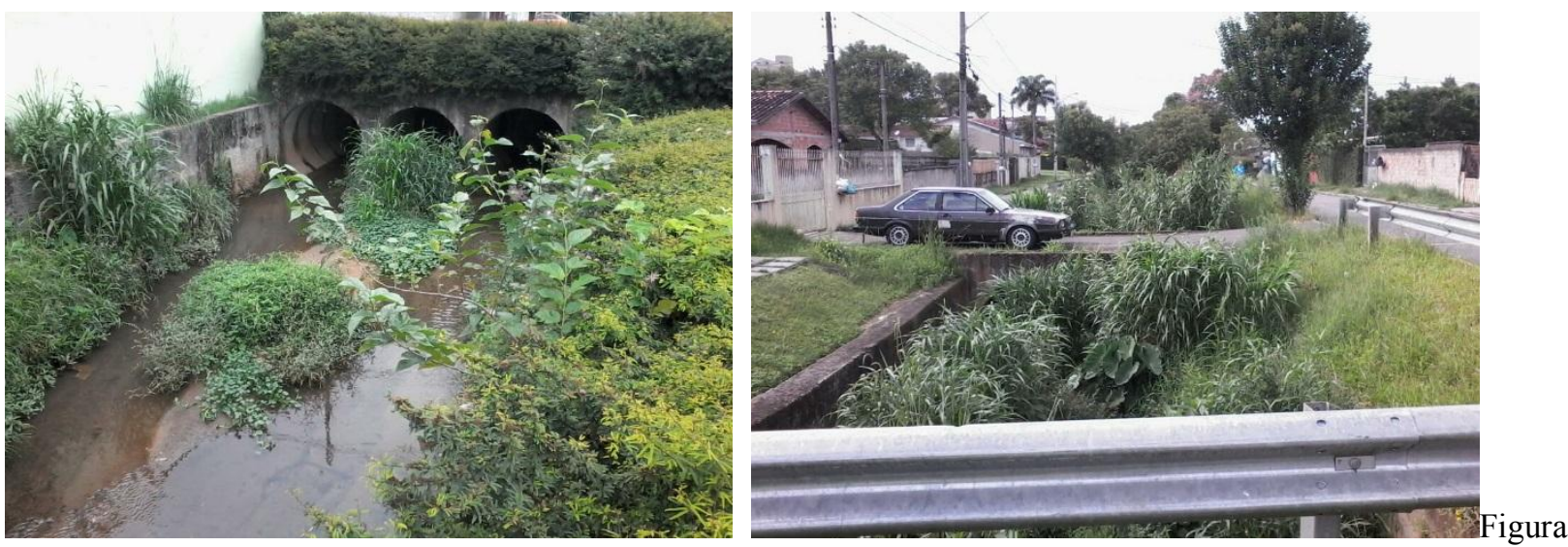

12 - Obras de intervenção no rio Belém. Esquerda: ao sul da unidade de saúde Vila Diana. Direita: próximo a esquina das ruas Hassan Mohamed Raad e Augusto dos Anjos. Fonte: Os autores (2017).
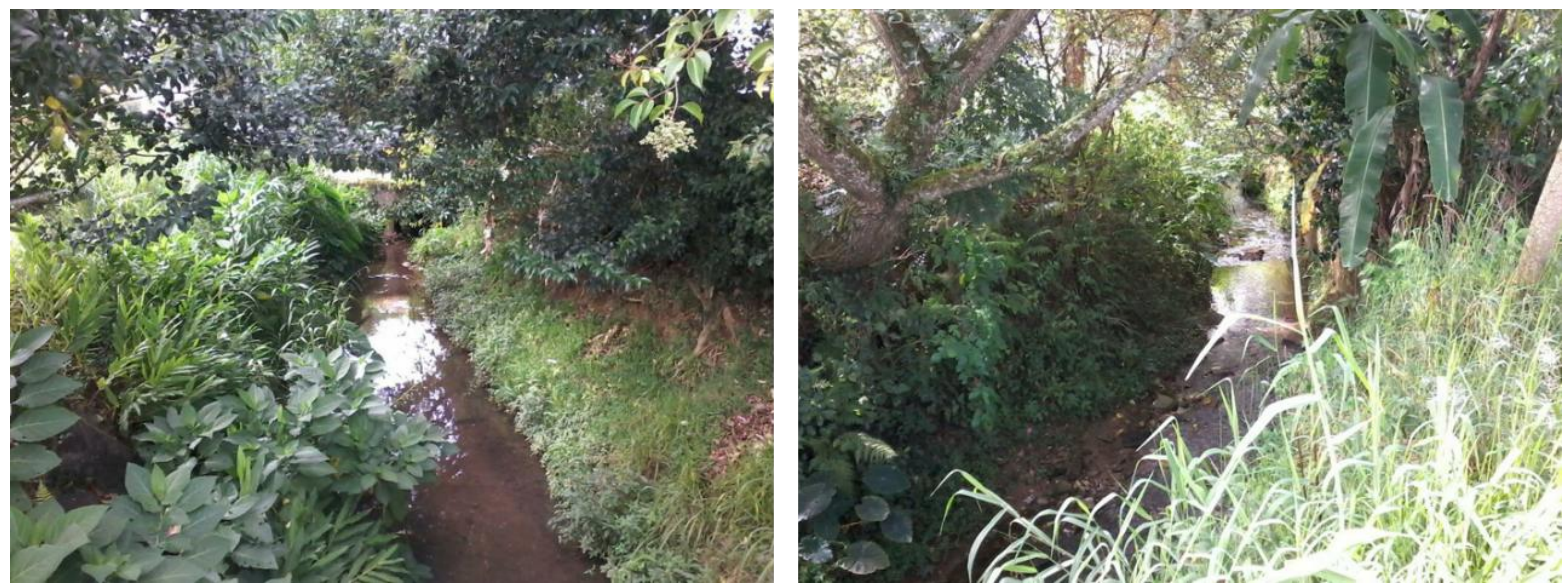

Figura 13 - Partes do rio Belém sem obras de intervenção. Esquerda: próximo à esquina das ruas Carmelina Cavassin e Hassan Mohamed Raad. Direita: próximo a esquina das ruas Aluísio de Azevedo e Prof. Leonardo Cobbe. Fonte: Os autores (2017).

Com a impermeabilização a capacidade de infiltração da água no solo é reduzida, e nota-se também um aumento a capacidade de escoamento devido ao material impermeável que facilita a movimentação da água de maneira mais rápida (TUCCI, 2002). 


\section{Conclusões}

Os resultados do trabalho, ainda baseados em uma análise preliminar,mostraram que a impermeabilização da superfície da terra está relacionada com a ocorrência de inundações na bacia do rio Belém, além disso, o aumento da urbanização irregular, muito próximo à nascente do rio pode agravar ainda mais a situação ambiental da região. As áreas com alta e média impermeabilização correspodem a mais da metade da área de estudo; as áreas permeáveis estão restritas à lotes não ocupados e ao parque da nascente.

A taxa de impermeabilidade do solo deve ser considerada nos estudos da qualidade ambiental e também como um instrumento a ser utilizada na gestão urbana, podendo ser uma medida de controle à ocupação. As consequências geradas pela impermeabilização da superfície da terra não só afeta as dinâmicas naturais do rio como também a população no entorno, assim, recomenda-se a adoção pelo poder público de práticas de planajamento urbano que estejam atreladas com políticas de sustentabilidade e qualidade ambiental, como por exemplo, a implantação de uma taxa máxima de impermeabilização por lote, calçadas arborizadas, pavimentação de material permeável, entre outras ações.

\section{Referências bibliográficas}

BOLLMANN, H. A.; EDWIGES, T. Avaliação da qualidade das águas do Rio Belém, Curitiba- PR, com o emprego de indicadores qualitativos e perceptivos. Engenharia sanitária ambiental. Volume 13 - nº4-out/dez 2008.

EDWIGES, T.; BOLLMANN, H. A. Programa interdisciplinar de pesquisa e intervenção na Bacia do Rio Belém: Monitoramento da qualidade das águas: Sub-bacia Barreirinha. Relatório Final apresentado ao Programa Institucional de Bolsas de Iniciação Científica da Pontifícia Universidade Católica do Paraná. Agosto de 2006, 62p.

FERREIRA, M. B. P. Cobertura da terra como indicador de qualidade ambiental urbana: estudo aplicado ao município de Curitiba-PR. 82f. Dissertação (Mestrado em Geografia). Universidade Federal do Paraná. Curitiba. 2015.

NUCCI, J. C. Qualidade ambiental e adensamento: um estudo de Planejamento da Paisagem do distrito de Santa Cecília (MSP). Tese de doutorado. Universidade de São Paulo. Programa de Pós-Graduação em Geografia Física. 1996.

Qualidade ambiental e adensamento urbano: um estudo de ecologia e planejamento da paisagem aplicado ao distrito de Santa Cecília (MSP). Curitiba: Ed. do Autor, 2008.

NUCCI, J. C.; FERREIRA, M. B. P.; VALASKI, S. Cobertura do solo e qualidade ambiental urbana como subsídios ao Planejamento da Paisagem. In: CONGRESSO IBERO-AMERICANO DE ESTUDOS TERRITORIAIS E AMBIENTAIS, 6., 2014, São Paulo. Anais... São Paulo: CIETA, 2014. p. 2886 - 2902.

TUCCI, C. E. Gerenciamento da Drenagem Urbana. Revista Brasileira de Recursos Hídricos. Volume 7, nº 1 , Jan/Mar 2002. 